\title{
The Effects of Preoperative Pain Education on the Decision to Discharge Patients Following Single-Incision Laparoscopic Appendectomy
}

\author{
Ji Won Seo ${ }^{1}$, Moon Jin Kim², Sung-HoonYoon ${ }^{3}$, Kwang Yeol Paik ${ }^{4}$, Sun Min Park ${ }^{4}$, Won Kyung Kang ${ }^{4}$, \\ Dosang Lee ${ }^{1}$, Chul Seung Lee ${ }^{1}$ \\ ${ }^{1}$ Department of Surgery, Seoul St. Mary's Hospital, College of Medicine, The Catholic University of Korea, Seoul; ${ }^{2}$ Department of Surgery, \\ Incheon St. Mary's Hospital, College of Medicine, The Catholic University of Korea, Incheon; ${ }^{3}$ Department of Surgery, St. Vincent Hospital, \\ College of Medicine, The Catholic University of Korea, Suwon; ${ }^{4}$ Department of Surgery, Yeoiudo St. Mary's Hospital, College of Medicine, The \\ Catholic University of Korea, Seoul, Korea
}

\begin{abstract}
Purpose: Few studies have analyzed the effects of preoperative pain education on the postoperative decision to discharge. The purpose of this study was to determine the effects of pain education and management on the decision to discharge patients after single-incision laparoscopic appendectomy (SILA).

Methods: We analyzed 135 patients who had undergone SILA for acute appendicitis between March 2017 and April 2018 in a single medical center. Of these, 72 patients (53.3\%) had received preoperative pain education (group 1), and 63 (46.7\%) had not (group 2). We compared perioperative outcomes and complications between the groups.

Results: Baseline characteristics of sex, age, body mass index, American Society of Anesthesiologist score, and systemic inflammation factors (neutrophil-lymphocyte ratio, C-reactive protein level) did not differ significantly between the groups. There were no postoperative complications for patients in either group. Perioperative consequences and pathologic findings were not significantly different between the groups; however, length of hospital was significantly shorter in group 1. Conclusion: Preoperative pain education in relation to postoperative pain management influenced the decision to shorten the postoperative hospital length of stay after SILA.
\end{abstract}

Keywords: Abdominal pain; Appendectomy; Laparoscopy; Postoperative pain

\section{INTRODUCTION}

Several studies have described the advantages of laparoscopic surgery [1-4], and laparoscopic appendectomy has subsequently emerged as a popular procedure with significantly less postopera-

Received: December 8, 2019 - Accepted: January 16, 2020

Correspondence to: Chul Seung Lee, M.D.

Division of Colorectal Surgery, Department of Surgery, Seoul St. Mary's Hospital, College of Medicine, The Catholic University of Korea, 222 Banpodaero, Seocho-gu, Seoul 06591, Korea

Tel: +82-2-2258-6095, Fax: +82-2-595-2282

E-mail: Icscolonoscopy@gmail.com

ORCID: https://orcid.org/0000-0002-4859-3015

(C) 2020 The Korean Society of Coloproctology

This is an open-access article distributed under the terms of the Creative Commons Attribution NonCommercial License (https://creativecommons.org/licenses/by-nc/4.0) which permits unrestricted noncommercial use, distribution, and reproduction in any medium, provided the original work is properly cited. tive pain, a shorter hospital stay, and a faster return to normal activities than the conventional procedure [5]. The single-incision laparoscopic appendectomy (SILA) technique has been developed and adopted by surgeons due to patient preference [6-11]. Moreover, in addition to patient cosmetic and psychological satisfaction, this technique has been shown to lead to a reduced length of hospital stay [7].

Factors likely to affect the length of hospital stay after laparoscopic appendectomy are postoperative pain, fever, nausea and vomiting, leukocytosis, whether the appendix was perforated, and preoperative position of the appendix. Conventional colorectal resection is associated with postoperative pain and long-term fatigue [12]. Pain education as well as postoperative pain management are critical for patient toleration of postoperative pain and for recovery. One study reported that preoperative education on pain reduced the requirement for pain relief [13]. 
Precise knowledge of the extent of postoperative pain is essential when deciding whether patients are to be discharged from the hospital. This study aimed to investigate the effects of preoperative pain education on determining discharge date after surgery.

\section{METHODS}

\section{Patients}

We retrospectively collected data from patients who had undergone appendectomy due to appendicitis from March 2017 to April 2018 at Department of Surgery, The Catholic University of Korea, Yeouido St. Mary's Hospital, Seoul in Korea. In total, 192 patients underwent laparoscopic appendectomy; 57 of whom had undergone 3-port appendectomy, also known as conventional laparoscopic appendectomy (CLA), whereas the remaining 135 patients had undergone single-port appendectomy, also known as SILA. Of the 135 patients who had undergone SILA, 72 were educated before surgery regarding postoperative pain (group 1), whereas 63 patients were not (group 2). Our study was approved by the Institutional Review Board (IRB) of The Catholic University of Korea (SC20RISI0005). Informed consent from patients to be included in this study was omitted according to the policy of our IRB.

The surgeon provided pain education about pain severity and type (wound pain, visceral pain, or somatic pain) and a pain control plan to the chosen patients. We informed patients of the discharge criteria and the methods used to control pain postoperatively, such as oral medication or intravenous medication (Table 1). Moreover, patients were informed that pain severity could be reduced and managed postoperatively during the hospital stay.

Laparoscopic appendectomy was performed for patients with both simple and complicated appendicitis, such as perforated appendicitis, abscess formation, and gangrenous appendicitis. $\mathrm{Pa}-$ tients aged $<15$ years old and pregnant women were excluded from the study. Intravenous second-generation cephalosporin was administered to all patients prior to induction of anesthesia. Discharge criteria comprised stable vital signs without fever $\left(<37.8^{\circ}\right)$, tolerance of diet, ability to walk unassisted, and a tolerable visual analogue scale (VAS) score $<3$.

\section{Technique}

All surgeries were performed by general surgical specialists at The
Catholic University of Korea, Yeoido St. Mary's Hospital. Under general anesthesia, patients were placed in a supine position to the left of the monitor, opposite the surgeon's position. A 1.0 to 1.5$\mathrm{cm}$-long vertical umbilical incision was made with dissection to the peritoneum. The commercial Glove port (431AT-2W, Nelis, Bucheon, Korea) was inserted through the umbilical incision, and a rigid 5-mm laparoscope was used. The subsequent surgical procedure and instruments used were the same for SILA and CLA techniques. The resected appendix was removed through the wound retractor. Appropriate irrigation with saline and hemostasis was ensured. In cases with appendiceal perforation or abscess formation, additional extensive irrigation was performed. A drain was inserted in the suprapubic or right lower quadrant area via the incisional wound when drainage was required. The umbilical fascia was closed with Vicryl 1.0 (Ethicon Inc., Cincinnati, $\mathrm{OH}$, USA). The skin incision was closed in subcuticular fashion using Vicryl 4.0 (Ethicon Inc.) and steri-strips (3M HealthCare, St. Paul, MN, USA) were applied to the umbilicus.

\section{Statistical analysis}

Statistical analysis was performed using IBM SPSS Statistics (ver. 24.0, IBM Corp., Armonk, NY, USA). Student t-test or Pearson chi-square and Fisher exact tests were used for between-group comparisons based on data type and distribution. Significant associations obtained on univariate analysis were included in a multivariable logistic regression analysis to identify independent predictors of postoperative hospital stay. For all analyses, a Pvalue $<0.05$ was considered statistically significant.

\section{RESULTS}

The SILA technique was performed on 135 patients. There was no significant difference in patient demographics of sex, age, American Society of Anesthesiologists (ASA) physical status classification, body mass index (BMI), and rate of complicated appendicitis between groups 1 and 2 (Table 2). The mean patient age in groups 1 and 2 was $39.2 \pm 15.5$ years and $40.7 \pm 13.6$ years, respectively $(\mathrm{P}=0.549)$. The mean $\mathrm{BMI}$ in groups 1 and 2 was $23.2 \pm 3.3 \mathrm{~kg} / \mathrm{m}^{2}$ and $23.4 \pm 4.0 \mathrm{~kg} / \mathrm{m}^{2}$, respectively $(\mathrm{P}=0.781)$. The rate of complicated appendicitis in groups 1 and 2 was $37.5 \%$ (27/72) and 22.2\% (14/63), respectively.

Comparing perioperative outcomes, start (day) of soft diet was

Table 1. Pain instructions for single-incision laparoscopic appendectomy

\begin{tabular}{|c|c|c|}
\hline Preoperative & Intraoperative & Postoperative \\
\hline Patient counseling and education ${ }^{a}$ & & $\begin{array}{l}\text { Aceclofenac } 100 \text { mg, every } 12 \mathrm{hr} \\
\text { Ketolac } 30 \mathrm{mg} \text { IV as needed }\end{array}$ \\
\hline
\end{tabular}

IV, intravenously.

${ }^{a}$ Only group 1 , see Supplementary data. 
not significantly different between group 1 ( $1.2 \pm 0.48$ days $)$ and group $2(1.2 \pm 0.45$ days $)(\mathrm{P}=0.749)$. The median VAS score 24-hours postoperatively was not significantly different between group $1(3.3 \pm 1.8)$ and group $2(3.1 \pm 1.7)(\mathrm{P}=0.730)$. The maximum VAS score during the 24-hour postoperative period was not significantly different between group $1(5.8 \pm 2.0)$ and group 2

Table 2. Patient demographics

\begin{tabular}{|c|c|c|c|}
\hline Variable & $\begin{array}{l}\text { Group 1 } \\
(n=72)\end{array}$ & $\begin{array}{l}\text { Group } 2 \\
(n=63)\end{array}$ & P-value \\
\hline Sex (male/female) & $34 / 38$ & $32 / 31$ & 0.405 \\
\hline Age (yr) & $39.2 \pm 15.5$ & $40.7 \pm 13.6$ & 0.549 \\
\hline ASA PS classification (\%) & & & 0.301 \\
\hline I & 67 (93.1) & $62(98.4)$ & \\
\hline$\|$ & $4(5.6)$ & $1(1.6)$ & \\
\hline III & $1(1.4)$ & $0(0)$ & \\
\hline Body mass index $\left(\mathrm{kg} / \mathrm{m}^{2}\right)$ & $23.2 \pm 3.3$ & $23.4 \pm 4.0$ & 0.781 \\
\hline \multicolumn{4}{|l|}{ Diagnosis (\%) } \\
\hline Suppurative $^{\mathrm{a}}$ & $51(70.8)$ & $49(77.8)$ & 0.358 \\
\hline Perforated ${ }^{b}$ & $14(19.4)$ & $7(11.1)$ & 0.183 \\
\hline Gangrenous $^{\mathrm{C}}$ & $11(15.3)$ & $15(23.8)$ & 0.620 \\
\hline Abscess $^{d}$ & $8(11.1)$ & $5(7.9)$ & 0.533 \\
\hline Preoperative WBC ( $/ \mu \mathrm{L})$ & $12,549.2 \pm 4,206.4$ & $12,348.4 \pm 3,722.5$ & 0.367 \\
\hline Preoperative CRP (mg/L) & $26.7 \pm 44.2$ & $25.6 \pm 46.3$ & 0.932 \\
\hline Complicated appendicitis ${ }^{e}$ & 27 (37.5) & 14 (22.2) & 0.054 \\
\hline
\end{tabular}

Values are presented as number only, mean \pm standard deviation, or number (\%). Group 1, patients with preoperative pain education; group 2, patients without preoperative pain education.

ASA PS, American Society of Anesthesiologists physical status; WBC, white blood cell; CRP, C-reactive protein.

aSuppurative appendicitis. 'Perforated appendicitis. 'Gangrenous appendicitis. dPeriappendiceal abscess. ${ }^{~} \mathrm{C}$ omplicated appendicitis included perforation, peritonitis, and/or abscess.
$(6.3 \pm 1.6)(\mathrm{P}=0.110)$

Postoperative hospital stay was shorter in group $1(1.9 \pm 0.97)$ than in group $2(2.9 \pm 1.6)(\mathrm{P}<0.001)$. Between the groups, postoperative complications and readmission rates were not significantly different. There was no occurrence of severe complications, defined using the Clavien-Dindo classification as morbidity grade $>$ III, in either group nor were there any postoperative deaths (Table 3 ).

Table 3. Perioperative outcomes

\begin{tabular}{lccc}
\hline Variable & $\begin{array}{c}\text { Group 1 } \\
(\mathrm{n}=72)\end{array}$ & $\begin{array}{c}\text { Group 2 } \\
(\mathrm{n}=63)\end{array}$ & P-value \\
\hline Operative time (min) & $15(20.8)$ & $19(30.2)$ & 0.213 \\
$\quad>60$ & $57(79.2)$ & $44(69.8)$ & \\
$\quad 360$ & $3(4.2)$ & $5(7.9)$ & 0.287 \\
Drain & $1.9 \pm 0.97$ & $2.9 \pm 1.6$ & $<0.001$ \\
Postoperative hospital stay (day) & $1.2 \pm 0.48$ & $1.2 \pm 0.45$ & 0.749 \\
Start of soft diet (postoperative day) & & & \\
VAS until postoperative day 1 & $3.3 \pm 1.8$ & $3.1 \pm 1.7$ & 0.730 \\
$\quad$ Median & $5.8 \pm 2.0$ & $6.3 \pm 1.6$ & 0.110 \\
$\quad$ Max & $1(1.4)$ & $3(4.8)$ & 0.249 \\
Superficial incisional SSI & $0(0)$ & $0(0)$ & - \\
Organ space SSI & $2(2.8)$ & $0(0)$ & 0.183 \\
Ileus & $0(0)$ & $0(0)$ & - \\
Severe complication ${ }^{\mathrm{a}}$ & $0(0)$ & $0(0)$ & - \\
Reoperation & $0(0)$ & $0(0)$ & - \\
Readmission within 30 days & $0(0)$ & $0(0)$ & - \\
\hline Mortality within 30 days & &
\end{tabular}

Values are presented as number (\%) or mean \pm standard deviation.

Group 1, patients with preoperative pain education; group 2, patients without preoperative pain education.

VAS, visual analogue scale for pain; SSI, surgical site infection.

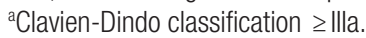

Table 4. Predictors of postoperative hospital stay ( $>2$ days) after single-incision appendectomy in univariable and multivariable logistic regression analyses

\begin{tabular}{|c|c|c|c|c|}
\hline \multirow{2}{*}{ Variable } & \multicolumn{2}{|c|}{ Univariate analysis } & \multicolumn{2}{|c|}{ Multivariate analysis } \\
\hline & OR $(95 \% \mathrm{Cl})$ & P-value & OR $(95 \% \mathrm{Cl})$ & P-value \\
\hline Age (>65 yr) & $1.78(0.38-8.31)$ & 0.466 & NA & \\
\hline Female sex & $1.01(0.48-2.10)$ & 0.987 & NA & \\
\hline Body mass index $\left(>25 \mathrm{~kg} / \mathrm{m}^{2}\right)$ & $1.06(0.45-2.49)$ & 0.773 & NA & \\
\hline Operative time (> $60 \mathrm{~min}$ ) & $1.13(0.49-2.61)$ & 0.773 & NA & \\
\hline Complicated appendicitis ${ }^{\mathrm{a}}$ & $2.42(1.11-5.25)$ & 0.026 & $5.90(2.03-17.19)$ & 0.001 \\
\hline Preoperative WBC (>12,000/ $\mu \mathrm{L})$ & $0.16(0.28-1.24)$ & 0.591 & NA & \\
\hline Preoperative CRP (>10 mg/L) & $1.47(0.70-3.07)$ & 0.309 & NA & \\
\hline Pain instruction (no) & $7.23(3.07-17.00)$ & $<0.001$ & $13.17(4.53-38.22)$ & $<0.001$ \\
\hline
\end{tabular}

$\mathrm{OR}$, odds ratio; $\mathrm{Cl}$, confidence interval; NA, not applicable; WBC, white blood cell; CRP, C-reactive protein.

${ }^{a}$ Complicated appendicitis included perforation, peritonitis, and/or abscess. 
In univariate analyses, pain education and complicated appendicitis on initial computed tomography were significantly associated with delayed postoperative hospital length of stay. Moreover, in multivariable analysis, lack of preoperative pain information $(\mathrm{P}<$ 0.001 ) and preoperative diagnosis of complicated appendicitis $(\mathrm{P}=0.001)$ were independent risk factors for longer postoperative hospital stay $(\mathrm{P}<0.001$; Table 4$)$.

\section{DISCUSSION}

Information concerning discharge criteria, surgical procedure, and postoperative patient management was obtained for all study patients. Both a specialist and a surgical resident participated in each surgical procedure, with the surgical resident being present for longer than half the operation time. No significant difference was found between groups in terms of sex, age, ASA physical status classification, BMI, and rate of complicated appendicitis; however, we observed a significant difference in length of hospital stay. Group 1 patients, who had received preoperative pain education, showed significantly reduced hospital stay compared to patients in group 2, who had not received preoperative pain education.

Single-port or 3-port appendectomy was performed according to the surgeon's preference. In cases of severe inflammation of the terminal ileum or cecum or generalized panperitonitis, a 3-port laparoscopy should be performed. To reduce heterogeneity due to surgical method, we excluded patients who underwent 3-port surgery and compared only patients who had undergone singleport surgery.

Our institution is a tertiary referral medical center; therefore, patients with simple appendicitis were often transferred to a local clinic when there are few surgeons or anesthetists. However, patients with severe appendicitis, such as complicated appendicitis, were likely to undergo surgery at our hospital. Therefore, the rate of complicated appendicitis was relatively high compared to that in other medical centers, where the rate has been reported to be $<10 \%$ [14].

Introduction of diagnosis-related group (DRG) systems where hospitals cover medical cost payments for patients undergoing appendectomy has been shown to reduce significantly the economic burden for patients in relation to medical costs nationwide [15]. Despite patients with appendectomy staying longer in hospital compared to the average length of hospital stay, their costs tend not to increase due to the DRG system [16]. However, some patients decline postoperative discharge from the hospital until complete recovery, despite lack of pain and fatigue. Our findings that preoperative pain education regarding postoperative pain and management affect length of patient hospital stay may reduce the number of such patients.

Some studies have reported on postoperative pain education, as this topic has emerged as an important issue $[12,13]$. Patient education usually includes information concerning pain and its man- agement and refers to all educational activities directed at patients and/or their families. Patient education aims to establish patient competence and confidence in undertaking health behaviors that are consistent with life plans and that support autonomous decision-making, whereby patient learning is assisted by an educator's teaching strategies and selected instructional material. In relevant studies, this education process has typically comprised 4 steps: (1) assessment of patient educational needs and potential barriers to learning; (2) setting educational objectives; (3) implementation using instructional methods and tools; and (4) evaluation of patient learning [17]. However, few studies have reported preoperative pain education for patients undergoing emergency surgery.

Our preoperative education program for patients included the following content regarding postoperative pain, pain control planning, effective pain control, and discharge criteria: "(1) You may feel more pain immediately after the surgery, but the pain will gradually decrease and will eventually desist; (2) Because the surgery is a single-port procedure, the pain will be concentrated at the umbilicus, and you will feel more pain than that experienced after a 3-port procedure; (3) For VAS score $>4$, you may be injected with an intravenous painkiller or you may be allowed to take a painkiller orally when you are capable of eating; and (4) You may be discharged if you can control your pain with oral medications alone." This education program aimed to provide patients in group 1 with a better understanding of postoperative pain and more appropriate postoperative pain control than those in group 2. The incidence of pain attributable to vague anxiety may be reduced by including the expected degree of pain among the discharge criteria described in the educational contents, which may consecutively reduce eventual delays in discharge.

Most patients in group 2 rejected discharge due to surgical site pain (VAS score <3). They mentioned that they were afraid of pain exacerbation when they returned home. Some patients who lived far from our hospital rejected discharge because they needed to arrange public transportation according to the train and express bus schedules. Furthermore, patients who had no family and lived alone refused to be discharged because they had no one to take care of them at home.

Factors affecting the decision to discharge a patient include patient level of consciousness, physical activity, hemodynamic stability, respiratory stability, postoperative pain assessment, and postoperative emetic symptoms. In univariate analysis, operation time and pain education were significant factors affecting hospital length of stay; in multivariable analysis, preoperative pain education was an independent factor affecting hospital length of stay.

This study had some limitations. First, this was a retrospective study with a small number of patients. Therefore, large-scale multi-center studies or a randomized control trial should be conducted to more clearly identify the factors related to hospital length of stay. Second, we did not analyze hourly pain score or quality of life between the 2 groups. Nevertheless, this study revealed a clear correlation between preoperative pain education 
and shortened hospital length of stay. Finally, other risk factors of postoperative pain, such as surgical incision length, were not measured. Nevertheless, all procedures were performed by experienced surgeons, and all incisions were made in the umbilicus. Surgical procedures, including the wound closure technique, did not vary.

In conclusion, preoperative pain education in relation to postoperative pain management for patients with appendicitis shortened the postoperative hospital length of stay.

\section{CONFLICT OF INTEREST}

No potential conflict of interest relevant to this article was reported.

\section{SUPPLEMENTARY MATERIALS}

Supplementary materials for this study are presented online (available at https://doi.org/10.3393/ac.2020.01.16).

\section{REFERENCES}

1. Kumar S, Jalan A, Patowary BN, Shrestha S. Laparoscopic appendectomy versus open appendectomy for acute appendicitis: a prospective comparative study. Kathmandu Univ Med J (KUMJ) 2016;14:244-8.

2. Sozutek A, Colak T, Dirlik M, Ocal K, Turkmenoglu O, Dag A. A prospective randomized comparison of single-port laparoscopic procedure with open and standard 3-port laparoscopic procedures in the treatment of acute appendicitis. Surg Laparosc Endosc Percutan Tech 2013;23:74-8.

3. Kargar S, Mirshamsi MH, Zare M, Arefanian S, Shadman Yazdi E, Aref A. Laparoscopic versus open appendectomy; which method to choose? A prospective randomized comparison. Acta Med Iran 2011;49:352-6.

4. Wang X, Zhang W, Yang X, Shao J, Zhou X, Yuan J. Complicated appendicitis in children: is laparoscopic appendectomy appropriate? A comparative study with the open appendectomy: our experience. J Pediatr Surg 2009;44:1924-7.

5. Golub R, Siddiqui F, Pohl D. Laparoscopic versus open appendectomy: a metaanalysis. J Am Coll Surg 1998;186:545-53.

6. Pan Z, Jiang XH, Zhou JH, Ji ZL. Transumbilical single-incision laparoscopic appendectomy using conventional instruments: the single working channel technique. Surg Laparosc Endosc Percu- tan Tech 2013;23:208-11.

7. Kim SJ, Choi BJ, Lee SC. Novel approach of single-port laparoscopic appendectomy as a solo surgery: a prospective cohort study. Int J Surg 2015;21:1-7.

8. Duza G, Davrieux CF, Palermo M, Khiangte E, Azfar M, Rizvi SAA, et al. Conventional laparoscopic appendectomy versus single-port laparoscopic appendectomy, a multicenter randomized control trial: a feasible and safe alternative to standard laparoscopy. J Laparoendosc Adv Surg Tech A 2019;29:1577-84.

9. Lee WS, Choi ST, Lee JN, Kim KK, Park YH, Lee WK, et al. Single-port laparoscopic appendectomy versus conventional laparoscopic appendectomy: a prospective randomized controlled study. Ann Surg 2013;257:214-8.

10. Frutos MD, Abrisqueta J, Lujan J, Abellan I, Parrilla P. Randomized prospective study to compare laparoscopic appendectomy versus umbilical single-incision appendectomy. Ann Surg 2013; 257:413-8.

11. Kim JH, Kim HY, Park SK, Lee JS, Heo DS, Park SW, et al. Singleincision laparoscopic appendectomy versus conventional laparoscopic appendectomy: experiences from 1208 cases of single-incision laparoscopic appendectomy. Experiences from 1208 cases of single-incision laparoscopic appendectomy. Ann Surg 2015;262: 1054-8.

12. Schwenk W, Böhm B, Müller JM. Postoperative pain and fatigue after laparoscopic or conventional colorectal resections: a prospective randomized trial. Surg Endosc 1998;12:1131-6.

13. Walker JA. What is the effect of preoperative information on patient satisfaction? Br J Nurs 2007;16:27-32.

14. Sartelli M, Baiocchi GL, Di Saverio S, Ferrara F, Labricciosa FM, Ansaloni L, et al. Prospective observational study on acute appendicitis worldwide (POSAW). World J Emerg Surg 2018;13:19.

15. Geissler A, Quentin W, Busse R. Heterogeneity of European DRG systems and potentials for a common EuroDRG system. Comment on "Cholecystectomy and Diagnosis-Related Groups (DRGs): patient classification and hospital reimbursement in 11 European countries”. Int J Health Policy Manag 2015;4:319-20.

16. Kim KH, Lee SC, Lee SK, Choi BJ, Jeong W, Kim SJ. Does Korea’s current diagnosis-related group-based reimbursement system appropriately classify appendectomy patients? Ann Surg Treat Res 2016;91:66-73.

17. Darling-Hammond L, Flook L, Cook-Harvey C, Barron B, Osher D. Implications for educational practice of the science of learning and development. Appl Dev Sci 2019;24:97-140. 